\title{
Estudo da correlação das características citológicas vaginais e os níveis séricos de estradiol e progesterona em leão africano (Panthera leo) mantidos em cativeiro
}

Guilherme Costa de Oliveira e SILVA ${ }^{1}$

Patrícia Espíndola Bretas BERBARE

Rogério Loesch

ZACCARIOTTI

Sandra Helena Ramiro

CORRÊA ${ }^{2}$

Cláudio Alvarenga de

OLIVEIRA ${ }^{1}$

Marcelo Alcindo de Barros

Vaz GUIMARÃES ${ }^{1}$

\section{Correspondência para:}

GHILHERMECOSTADEOLIVEIRAESILVA Rua: Três, 28, Refúgio - Atibaia/SP CEP: $12946-752$

jamanta65@ig.com.br

Recebido para publicação: 19/04/2005 Aprovado para publicação: 21/09/2005

\author{
1 - Departamento de Reprodução Animal da Faculdade de Medicina \\ Veterinária e Zootecnia da Universidade de São Paulo - São Paulo,SP \\ 2 - Fundação Parque Zoológico de São Paulo - São Paulo/SP
}

\section{Resumo}

Foram estudados 11 exemplares de fêmeas adultas de leões africanos (Panthera leo) mantidas na Fundação Parque Zoológico de São Paulo (FPZSP) quanto às características da citologia vaginal, níveis hormonais (estradiol e progesterona) e suas correlações. As características celulares vaginais encontradas nas leoas foram semelhantes às descritas para os felinos domésticos. Adotando-se os padrões hormonais de estradiol (E2) e progesterona (P4) que definem as fases do ciclo estral de felinos domésticos, foi possível caracterizar três fases do ciclo ovariano nas leoas: Diestro, Estro e Interestro. O nível médio de E2 sérico encontrado na fase caracterizada como Estro $(23,33+/-2,92 \mathrm{pg} / \mathrm{ml})$, apresentou-se mais alto do que nas outras fases estudadas e o nível médio de P4 sérico encontrado na fase de Diestro $(20,12+/$ - 17,55 $\mathrm{ng} / \mathrm{ml}$ ) apresentou diferença estatística significativa em comparação às outras fases estudadas. Demonstrou-se também, a existência de correlação de intensidade média entre os níveis séricos de $\mathrm{P} 4$ e o número de células superficiais corneificadas $(r=-0,603$ e $p=0,0496)$ e entre $P 4$ e células intermediárias $(r=0,637$ e $p=0,0350)$. Também foi demonstrada a existência de correlação negativa de forte intensidade entre os números de células superficiais corneificadas e o de células intermediárias. $(r=-0,979 \mathrm{e} p<0,0001)$. Concluimos que a correlação entre as características celulares vaginais e os níveis séricos de progesterona e estradiol permitiram-nos determinar três diferentes fases do ciclo ovariano da fêmea de leão africano.

\section{Introdução}

Os ecossistemas naturais de florestas, savanas, pradarias e pastagens, desertos, tundras, rios, lagos e mares contêm a maior parte da diversidade biológica da Terra. Os esforços visando a conservação da diversidade biológica aumentaram muito nos últimos 20 anos, mesmo assim a destruição e a perda da diversidade biológica continuam acontecendo. A ação humana sobre as diferentes espécies de felinos silvestres, se dá pela caça e a captura de forma legal ou ilegal que, juntamente com a degradação dos habitats naturais, levam a um declínio das suas populações ${ }^{1}$. Neste contexto, os zoológicos são responsáveis pela manutenção de animais silvestres em cativeiro, atuando de várias formas na conservação das espécies, promovendo a reprodução em cativeiro e realizando atividades em educação ambiental, aumentando o interesse, afeição e conhecimento do público em geral sobre a fauna silvestre. $O$ desempenho reprodutivo destas espécies em cativeiro, a chamada reprodução ex-situ, depende de condições ideais de alojamento, nutrição, medicina 
preventiva e da adaptação dos indivíduos a estas condições. Muitas espécies, além disto, dependem da aplicação de técnicas de reprodução assistida para efetivamente se reproduzir em cativeiro. Para tanto, são necessários estudos básicos que descrevam as características endócrino-reprodutivas de cada uma das espécies estudadas.

O Leão Africano (Panthera leo) é um mamífero pertencente à Família Felidae, pesando de 120 a $200 \mathrm{~kg}$ e com comprimento total variando de 2,6 a 3,3 metros $^{2}$. Os leões são os únicos felinos que apresentam um sistema social altamente estruturado, denominado "pride", de caráter matrilocal". Este é formado por um grupo de 2 a 18 fêmeas geneticamente aparentadas e suas crias, sem relação de dominância entre elas, sendo comum a sincronização dos estros ${ }^{4}$. A sociedade é liderada temporariamente por um macho ou por uma coalizão de 2 a 9 machos, onde todos eles copulam inúmeras vezes com as fêmeas em estro, até que uma nova coalizão assuma o controle do "pride" e os expulse $e^{3}$. As múltiplas cópulas são características da espécie, cujas fêmeas apresentam ovulações induzidas e são poliéstricas anuais.

Mesmo não sendo uma espécie nativa do Brasil, o leão africano é um excelente modelo biológico para estudos reprodutivos, uma vez que existe em número expressivo em cativeiro e é uma das espécies mais bem adaptadas a esta condição, com grande facilidade para reproduzir-se nas mais adversas condições de manejo. Esta espécie possui parentesco filogenético com espécies de felinos brasileiros, como a onça-pintada (Panthera onca), que apresenta expressiva redução de populações em vida livre, pelas razões já expostas. O presente estudo visou avaliar a correlação entre as características celulares vaginais e os níveis séricos de estradiol e progesterona em leão africano (Panthera leo), mantidos em cativeiro.

\section{Material e Métodos}

Foram estudados 11 exemplares de fêmeas adultas de leão africano (Panthera leo) mantidos pela Fundação Parque Zoológico de São Paulo (FPZSP). Os animais foram anestesiados após jejum de 24 horas, com a associação de Cloridrato de Quetamina (Ketalar ${ }^{\circledR}$ Parker-Davis/ Warner-Lambert, EUA) na dose 10,0mg/ $\mathrm{kg}$ associados a $1,0 \mathrm{mg} / \mathrm{kg}$ de Cloridrato de Xilazina (Rompun ${ }^{\circledR}$ Bayer S.A., Brasil), administrados por via intramuscular ou com Cloridrato de Tiletamina associado ao Zolazepam (Zoletil50 ${ }^{\circledR}$ Virbac do Brasil Ind. Com. Ltda, Brasil) na dose de 10,0mg/kg, via intramuscular, a critério dos Médicos Veterinários da FPZSP

Imediatamente após a contenção do animal foi colhida a primeira amostra de sangue por venopuntura da safena, em tubo esterilizado com vácuo $\left(\right.$ Vacutainer $\left.^{\circledR}\right)$. A partir da primeira colheita de sangue, foram realizadas mais três colheitas em intervalos de 15 a 20 minutos. O sangue assim colhido ficou em repouso a temperatura ambiente até que ocorresse a retração do coágulo (40 minutos em média), quando então foi centrifugado a $300 \mathrm{G}$ por quinze minutos. Após a separação do soro sangüíneo, cada amostra foi acondicionada em criotubos plásticos, congelada e mantida em freezer a $-29^{\circ} \mathrm{C}$ até a realização das dosagens hormonais.

Em seguida, após higienização da região do períneo e com o auxílio de um espéculo vaginal esterilizado, foi introduzido um "swab" estéril umedecido com solução salina estéril através do canal vaginal. O "swab" introduzido foi rotado na mucosa vaginal e retirado em seguida, quando foi novamente rotado sobre duas lâminas de vidro. Após secagem ao ar, as lâminas foram fixadas em solução 1:1 de metanol/éter.

Os métodos utilizados para a coloração das lâminas obtidas foram o método de Shorr ${ }^{7}$ e o Panótico Rápido (Kit para Panótico Rápido, Laborclin ${ }^{\circledR}$ Produtos para Laboratórios Ltda, Brasil). A caracterização dos tipos celulares encontrados foi feita segundo Herron ${ }^{2}$ num estudo de citologia vaginal durante as fases do ciclo 
estral no gato doméstico, caracterizando as células em parabasais (CP), intermediárias (CI) e superficiais corneificadas (CSC), estas últimas podendo apresentar núcleo picnótico ou ausente. A contagem e caracterização dos tipos celulares vaginais (200 células/lâmina) foi realizada no Laboratório de Citologia Vaginal do Departamento de Reprodução Animal da FMVZ/USP, com o uso de Microscópio de luz (Eclipse E600 Nikon ${ }^{\circledR}$ ). As dosagens hormonais foram realizadas no Laboratório de Dosagens Hormonais do Departamento de Reprodução Animal da FMVZ/USP, pela técnica de Rádioimunoensaio (RIE) em fase sólida, utilizando-se Kits Comerciais (Cont-aCount $^{\circledR}$ DPC), no qual os hormônios marcados com $\mathrm{I}^{125}$ competem com o hormônio não marcado da amostra pelos sítios de ligação no anticorpo específico.

$\mathrm{Na}$ análise estatística, foram calculados as médias e os desvios-padrão dos valores de estradiol e progesterona obtidos para cada animal e foi estudada a possível correlação entre estes valores e as características celulares vaginais.

Os dados obtidos foram analisados com o uso do programa SAS System for Windows (SAS Institute Inc., Cary, NC, USA, 2000). Através do aplicativo Guided Data Analysis, os dados foram testados quanto à normalidade dos resíduos e homogeneidade das variâncias e caso não obedecessem a estas premissas, eram transformados. Se a normalidade não fosse obtida, empregarse-ia então, o procedimen-to NPAR1WAY de análise de variância não paramétrica.

Para a descrição dos resultados, foram utilizados as médias, os desviospadrão e os níveis de significância (p) dos dados originais, quando estes obedecessem às premissas e dos dados transformados, quando não.

Para a comparação entre as médias de níveis séricos hormonais das fases do ciclo ovariano foi utilizado o Teste de Tukey com $\mathrm{p}<0,05 . \mathrm{Na}$ avaliação das correlações entre os níveis séricos hormonais e as diferentes populações celulares foi utilizado o Coeficiente de Correlação de Pearson com $\mathrm{p}<0,05$.

Como parâmetros hormonais para a caracterização das fases do ciclo ovariano, foram utilizados os valores de progesterona (P4) e estradiol (E2) séricos do gato doméstico: Estro, P4 $<1,5 \mathrm{ng} / \mathrm{ml}$ e E $2>$ 20pg/ml; Diestro, P4 > 1,5ng/ml e E2 < $20 \mathrm{pg} / \mathrm{ml}$ e Interestro, P4 $<1,5 \mathrm{ng} / \mathrm{ml}$ e E2 $<20 \mathrm{pg} / \mathrm{ml}$, segundo Verhage, Beaner e Brenner $^{7}$ e Johnston, Root Kustritz e Olson ${ }^{8}$.

\section{Resultados}

Com base no critério adotado, foi

Tabela 1 - Valores hormonais séricos (Média+/-SD) e porcentagem de tipos celulares vaginais (Média+/-SD) encontrados em leoas (Panthera leo), caracterizando as fases de DIESTRO, ESTRO e INTERESTRO. São Paulo, 2004

\begin{tabular}{|c|c|c|c|c|c|}
\hline \multirow[t]{2}{*}{ Fases } & \multicolumn{2}{|c|}{ Níveis Hormonais Médios } & \multicolumn{3}{|c|}{$\%$ Média de Tipos Celulares Vaginais } \\
\hline & $\mathrm{P} 4(\mathrm{ng} / \mathrm{ml})^{1}$ & $\mathrm{E} 2(\mathrm{pg} / \mathrm{ml})^{2}$ & $\mathrm{CSC}^{3}$ & $\mathrm{Cl}^{4}$ & $\mathrm{CP}^{5}$ \\
\hline $\begin{array}{c}\text { DIESTRO } \\
P 4>1,5 \mathrm{mg} / \mathrm{ml} \\
E 2<20 \mathrm{pg} / \mathrm{ml}\end{array}$ & $20,12+/-17,55$ & $6,32+/-1,23^{b}$ & $\begin{array}{c}57,25+/- \\
30,19\end{array}$ & $\begin{array}{c}37,92+/- \\
29,49\end{array}$ & $4,83+/-0,95$ \\
\hline $\begin{array}{c}\text { ESTRO } \\
P 4< \\
1,5 \mathrm{mg} / \mathrm{ml} \\
\mathrm{E} 2>20 \mathrm{pg} / \mathrm{ml}\end{array}$ & $0,88+/-0,31^{a}$ & $23,33+/-2,92^{B}$ & $99,63+/-0,48$ & $0,38+/-0,48$ & $0,00+/-0,00$ \\
\hline $\begin{array}{c}\text { INTERESTRO } \\
P 4< \\
1,5 \mathrm{mg} / \mathrm{m} / \\
E 2<20 \mathrm{pg} / \mathrm{ml}\end{array}$ & $0,73+/-0,14^{a}$ & $7,62+/-4,31^{b}$ & $\begin{array}{c}86,50+/- \\
16,84\end{array}$ & $7,69+/-8,62$ & $5,81+/-8,37$ \\
\hline
\end{tabular}

4-Cl: Células Intermediárias; 5-CP: Células Parabasais. Letras sobrescritas indicam diferença estatística- $A$ a: $P=0,0024$; B/b: P=0,0002. 


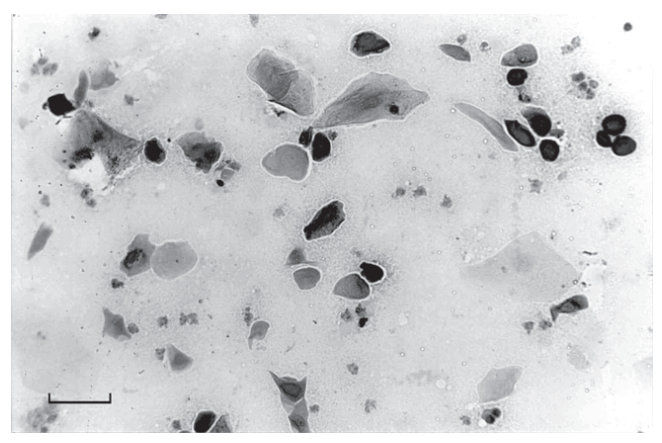

Figura 1 - Aspecto geral do esfregaço vaginal de leoas (Panthera leo) na fase de diestro. Cada barra equivale à medida de $1 \mathrm{~mm}$ (Coloração: Shorr; Objetiva: 20x)

possível caracterizar três diferentes fases do ciclo estral no grupo de leoas estudadas (Tabela 1), a saber, Diestro ( $\mathrm{n}=3)$, Estro ( $\mathrm{n}$ =4) e Interestro $(\mathrm{n}=4)$.

Para a comparação entre as médias de progesterona sérica (P4) nas diferentes fases do ciclo ovariano, uma vez que os resultados não obedeceram às premissas da normalidade dos resíduos e homogeneidade das variâncias, os dados obtidos foram transformados para $1 / \mathrm{P} 4$, segundo recomendação do programa estatístico utilizado. A média dos dados transformados do Diestro foi significativamente maior do que nas outras duas fases $(p=0,0024)$. Entre as fases de Estro e Interestro não houve diferença $(p>0,05)$.

A comparação das médias dos valores de estradiol sérico (E2) nas três fases do ciclo ovariano, revelou que o nível de estradiol na fase de Estro foi significativamente maior do que nas outras duas fases $(p=0,0002)$, sendo que entre o Diestro e o Interestro não houve diferença significativa $(p>0,05)$.

Não foi possível analisar a presença de correlação entre as variáveis considerando-se cada fase isoladamente devido ao baixo número amostral. A análise foi realizada considerando-se o total das amostras nas três fases, obtendo-se, após o cálculo do Coeficiente de Correlação de Pearson (r) com os correspondentes níveis de significância (p), as seguintes correlações: P4 e CSC ( $r=-0,603 ; p=0,0496) ;$ P4 e CI

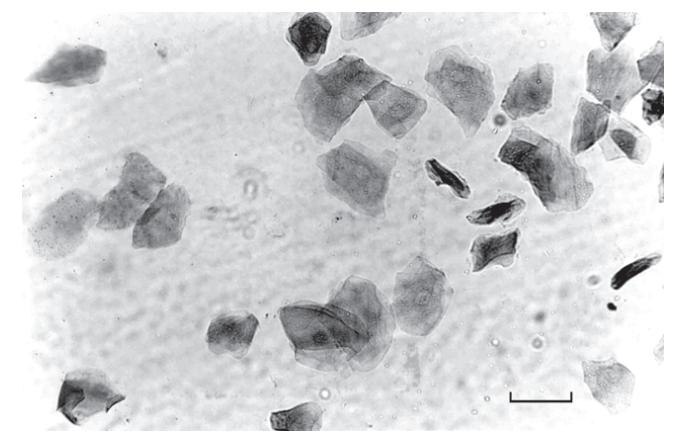

Figura 2 - Aspecto geral do esfregaço vaginal de leoas (Panthera leo) na fase de estro. Cada barra equivale à medida de $1 \mathrm{~mm}$. Colooração: Shorr; Objetiva: 20x)

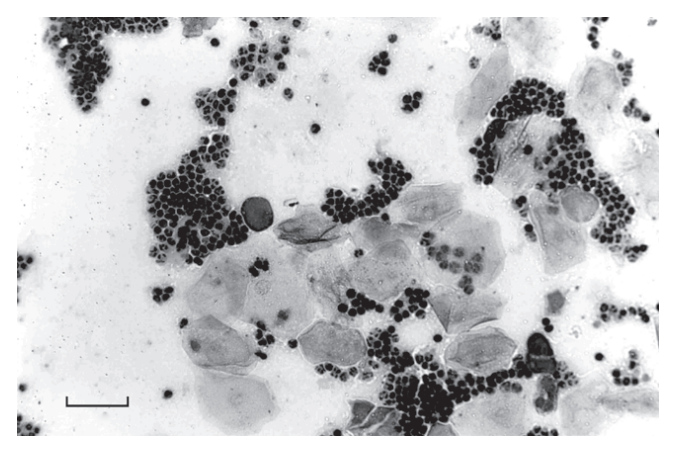

Figura 3 - Aspecto geral do esfregaço vaginal de leoas (Panthera leo) na fase de interestro. Cada barra equivale à medida de $1 \mathrm{~mm}$. Colooração: Shorr; Objetiva: 20x)

$(\mathrm{r}=0,637 ; \mathrm{p}=0,0350) ;$ CSC e CI $(\mathrm{r}=$ $0,979 ; \mathrm{p}<0,0001)$.

A Figura 1 apresenta o aspecto geral do esfregaço vaginal característico de cada fase do ciclo estral em leoas.

\section{Discussão}

Ambos os métodos empregados para a coloração das lâminas forneceram resultados satisfatórios. O método de Shorr apresentou uma melhor qualidade quanto à definição dos tipos celulares, em virtude da diferença de coloração existente entre o citoplasma de uma Célula Parabasal ou Intermediária e o de uma Célula Superficial. As primeiras se apresentavam com diferentes graus de basofilia enquanto que as células superficiais apresentavam tons variados de eosinofilia devido a progressiva queratinização. O método do Panótico provou ser uma boa alternativa de coloração pois seu 
uso já é bem difundido, de fácil execução e rápido. Deve-se ter o cuidado de filtrar os reagentes do Panótico a fim de se reduzir a quantidade de precipitados (artefatos de técnica) que se depositam na lâmina, dificultando a avaliação citológica.

Em relação às características citológicas vaginais das leoas, pode-se dizer que as células apresentam características semelhantes às das espécies domésticas de carnívoros mais estudadas como a canina e a felina. No presente estudo, as colheitas de material vaginal foram bem sucedidas, sendo a quantidade de material obtido suficiente para uma perfeita avaliação das características citológicas vaginais.

Analisando os resultados das dosagens séricas de Estradiol (E2) e Progesterona (P4), observou-se que os níveis hormonais obtidos foram semelhantes (em média) aos níveis descritos em literatura para felinos domésticos ${ }^{7,8,9}$. Desta forma foi possível utilizar o mesmo critério para caracterizar três diferentes fases do ciclo ovariano, a saber: Estro, Diestro e Interestro.

O nível médio de estradiol sérico (E2) encontrado na fase caracterizada como Estro, apresentou-se maior do que nas outras duas fases estudadas $(p=0,0002)$. Verificou-se também que não houve diferença estatística quanto aos níveis médios de estradiol entre as fases de Diestro e Interestro ( $p>0,05)$. No caso dos níveis médios de progesterona sérica (P4), os dados obtidos demonstraram diferença significativa entre os níveis do Diestro e as outras duas fases $(p=0,0024)$, sem haver, no entanto, diferença entre os níveis deste hormônio entre estas duas últimas fases ( $\mathrm{p}>0,05)$.

Quando a progesterona e o estradiol mostraram-se baixos pelo critério adotado, isto foi interpretado como Interestro, uma vez que estes níveis não seriam compatíveis com a ocorrência de ovulação e nem de maturação folicular. O Anestro foi descarta-do pela presença em grande quantidade de células superficiais corneificadas, o que suge-re, possivelmente, o início do Interestro ${ }^{8}$.

Quando consideradas todas as três fases, houve correlação positiva de intensi-dade média entre os níveis de progesterona sérica (P4) e células intermediárias (CI), negativa de intensidade média entre P4 e células superficiais corneificadas (CSC) e negativa de forte intensidade entre CSC e CI. Estes resultados são compatíveis com o esperado para mamíferos carnívoros domésticos, para os quais o alto nível de progesterona caracteriza a ocorrência de ovulação, portanto o Diestro, quando um aumento do percentual de células inter-mediárias e redução das superficiais cornei-ficadas é esperado ${ }^{8}$.

$\mathrm{Na}$ fase de Estro, foi possível encon-trar uma grande predominância de células superficiais comeificadas associada ao alto nível de estradiol, como já descrito para espécies domésticas ${ }^{8}$. No entanto não foi possível demonstrar a existência de correlação estatística devido ao baixo número amostral utilizado.

A fase de Interestro, apesar de bem caracterizada pelos níveis de progesterona e estradiol séricos (P4 < 1,5ng/ml e E2 $<20 \mathrm{pg}$ / $\mathrm{ml})$ como citado por Verhage, Beamer e Brenner $^{7}$ e Johnston, Root Kustritz e Olson ${ }^{8}$, não apresentou as carac-terísticas típicas de celularidade, quando seria esperado um predomínio de CI e encontrou-se uma ampla maioria de CSC. Este aspecto pode estar refletindo o início da fase de Interestro, como já sugerido.

Do ponto de vista comportamental, da mesma forma que para felinos domés-ticos, as leoas apresentam o comportamento característico de rolar, vocalizar, esfregar-se em objetos e nos próprios machos, quando no proestro e estro, sendo que as cópulas ocorrem exclusivamente durante o estro.

\section{Conclusão}

- Os métodos tintoriais empregados mostraram-se satisfatórios para a análise citológica vaginal em leoas.

- As características celulares vaginais das leoas apresentaram-se de forma semelhante às de outras espécies de carnívoros domésticos.

- Foram caracterizadas três fases do ciclo ovariano da leoa.

- Demonstrou-se a existência de correlação entre os níveis séricos de progesterona e duas características celulares. 
- Demonstrou-se também a existência de correlação entre células superficiais corneificadas e células intermediárias.
Recomenda-se que o trabalho seja continuado com um aumento do número amostral para melhor caracterização dos aspectos estudados.

\section{Vaginal citology, serum estradiol and progesterone: a correlation study on captive African lions (Panthera leo)}

\section{Abstract}

Eleven captive adult female African lions (Panthera leo) at the Fundação Parque Zoológico de São Paulo were blood sampled in order to assess the serum hormone levels (estradiol and progesterone) and their correlation with the vaginal citology. The morphological and stainning characteristics of vaginal cells were similar to those described for domestic cats. Based on hormonal profiles of estradiol and progesterone described for domestic cats, three different phases for the ovarian cycle of the lionesses were clearly described: diestrus, estrus and interestrus. The mean serum estradiol concentrations in the estrus $(23,33+/-2,92 \mathrm{pg} / \mathrm{ml})$ were significantly higher than in diestrus and interestrus. The mean serum progesterone values in diestrus $(20,12$ $+/-17,55 \mathrm{ng} / \mathrm{ml}$ ) were significantly higher than in estrus and interestrus. There were correlations between progesterone values and the number of superficial cornified vaginal cells $(r=-0,603$ and $p=$ $0,0496)$ and between progesterone and intermediate cells $(r=0,637$ and $p=0,0350$ ). There were also a strong negative correlation between the number of superficial cornified vaginal cells and intermediate cells $(r$ $=-0,979$ e $p<0,0001)$. It concluded that the correlations between vaginal cells and the serum estradiol and progesterone levels allowed us to identify three different phases of the ovarian cycle in female African lion.

\section{Referências}

1 BROWN, J. L. et al. Developmental changes in pituitary-gonadal function in free-ranging lions (Panthera leo) of the Serengeti Plains and Ngorongoro Crater. Journal of Reproduction and Fertility, v. 91, p. 29-40, 1991.

2 HERRON, M. A. Feline vaginal cytologic examination. Feline Practice, v. 7, p. 36-39, 1977.

3 JACKSON, P. Saving the cats - the IUCN/SSC cat specialist group. International Zoo News, v. 36, p. 17 19, 1989.

4 JOHNSTON, S. D.; ROOT KUSTRITZ, M. V.; OLSON, P. N. S. Canine and feline theriogenology. Philadelphia: W. B. Saunders, 2001.

5 PUSEY, A. E., PACKER, C. The evolution of sexbiased dispersal in lions. Behaviour, v. 101, p. 275 310, 1987.

6 SHILLE, V. M.; LUNDSTRÖM, K. E.; STABENFELDT, G. H. Follicular function in the domestic cat as determined by estradiol-17ß concentrations in plasma: relation to estrous behavior and cornification of
Key words:

Panthera leo.

African lion.

Vaginal citology.

Estradiol.

Progesterone . exfoliated vaginal epithelium. Biology of Reproduction v. 21, p. 953-963, 1979.

7 SHORR, E. A. A new technic for staining vaginal smears: III. A single diferential. Science, v. 94, n. 2449 p. 545-546, 1941.

8 SMUTS, G. L.; ROBINSON, G. A.; WHYTE, I. J. Comparative growth of wild male and female lions (Panthera leo). Journal of Zoology, v. 190, p. 365-373, 1980.

9 VERHAGE, H. G.; BEAMER, N. B.; BRENNER, R. $M$. Plasma levels of estradiol and progesterone in the cat during polyestrus, pregnancy and pseudopregnancy. Biology of Reproduction, v. 14, p. 579-585, 1976. 